\title{
RESENHA
}

Versão original| DOI: http://dx.doi.org/10.1590/S0034-759020210608

\section{A CIDADE EXISTE E RESISTE: EXPANDINDO A DINÂMICA ORGANIZACIONAL}

\author{
CIDADES E ESTUDOS ORGANIZACIONAIS: UM DEBATE NECESSÁRIO \\ Luiz Alex Silva Saraiva e Alessandro Gomes Enoque (Orgs.). Ituiutaba/MG, Brasil: Barlavento, 2019.433 p.
}

A abordagem das cidades nos estudos de gestão tem trilhado caminhos desde as publicações seminais no Brasil (Fischer, 1996, 1997; Mac-Allister, 2004), que visam incorporar questões sociais, políticas, econômicas e culturais ao âmbito da gestão organizacional por uma perspectiva de contexto crítico e simbólico. Levando em consideração o apelo por mais discussões na interdisciplinaridade que articulem o tema das cidades com as perspectivas das ciências administrativas, a obra Cidades e Estudos Organizacionais: um debate necessário sintetiza a produção acadêmica a partir do esforço para ampliar esse debate na academia. Na urgência de compreender o espaço urbano e a produção da cidade por diferentes lentes, entre elas os Estudos Organizacionais, a obra considera a cidade como organização nos seus distintos processos de organizar associada ao saber prático e uma posição reflexiva de gestão.

O livro, que está disponível no formato eletrônico, por meio de download gratuito à comunidade, é composto por nove capítulos em forma de artigos e tem como fio condutor a preocupação de diferentes pesquisadores para problematizar a cidade para além da noção de espaço e fronteiras físicas, assim ampliando e expandindo o conceito de organização. Foi organizado pelos professores Luiz Alex Silva Saraiva (UFMG) e Alessandro Gomes Enoque (UFU), que carregam em suas pesquisas as abordagens interdisciplinares dos Estudos Organizacionais, sobretudo a respeito de estudos sobre as cidades. Dessa maneira, a obra em questão desvela as discussões dos autores ao articular diferentes abordagens que vão desde as práticas do espaço urbano, passando pelas dinâmicas sociourbanas, pelas relações de poder, pelas questões de disputas, pelos grupos de resistência, pelas sociabilidades e pelo planejamento urbano.

"As cidades nos Estudos Organizacionais como resistência e reação sócio-espaciais", subtítulo do prefácio, é um convite para embarcar na leitura em que Ana Paula Baltazar, professora associada da Escola de Arquitetura e Design da UFMG, provoca o leitor a refletir sobre a extinção do Ministério das Cidades em 2019 e, consequentemente, o desmonte das políticas públicas socioespaciais. Esse prefácio configura-se como uma porta de entrada que introduz todo o conteúdo do livro diluído em seus capítulos e situa o leitor no núcleo das discussões. Os diferentes textos representam uma resposta ao clamor por um debate necessário entre as cidades e os Estudos Organizacionais por um prisma que envolve sujeitos ativos, cultura e diferenças, multiterritorialidades, participação popular e simbolismos, empreendedorismo local e organização de espaços coletivos, compondo uma agenda de pesquisa de diferentes áreas do saber, entre as quais se inserem os Estudos Organizacionais.

A proposta de "um debate necessário" continua sendo entregue ao leitor quando, no primeiro capítulo, o autor reconstrói um diálogo que sistematiza a literatura sobre 
os estudos de cidades para além das abordagens convencionais como a geografia e o urbanismo, por exemplo. Dessa forma, o autor aproxima-se de áreas interdisciplinares do conhecimento, entre elas a Antropologia Urbana, a Sociologia Urbana, as Artes e a Psicologia Social, por exemplo, para construir uma discussão tangente ao campo da Administração, em especial aos Estudos Organizacionais. O autor demonstra que essa relação é uma "contínua construção", explicitando como cada uma dessas áreas do conhecimento pode se aproximar da gestão nas cidades ao compreender a dinâmica urbana que confere à cidade uma abordagem específica nos meandros das discussões sobre: i) disputas por espaços; ii) lugar de experiências e sociabilidades; e iii) desigualdades sociais e segregações diversas. Dessa forma, o capítulo abre uma trilha para que os demais autores percorram as inquietações propostas na obra.

Os demais capítulos cumprem o prometido na introdução da obra. Para além do capítulo que discute a relação entre organização e cidade, a organicidade como método de representação urbana, a obra também aborda as tensas relações de poder e a concepção das favelas como organização/ desorganização do espaço social, compreendendo: i) como um grupo social pode territorializar a cidade; ii) abordagem dos grupos sociais como atores relevantes na construção do planejamento urbano; iii) reflexão sobre o fato de que as lutas acontecem de diferentes formas, indo além da noção de organização. Essas diferentes questões dão respaldo para a discussão sobre a dinâmica urbana das transformações nas cidades ancoradas nos conceitos de espaço, lugar, identidade, desterritorialização e reterritorialização. Além disso, os capítulos seguem coroando o desenvolvimento de um enredo pautado no pensamento crítico que problematiza o crescimento da cidade para atender apenas a interesses econômicos privados, e pautando a reorganização e a reprodução do espaço urbano e os interesses a ele inerentes. A obra é encerrada com discussões relevantes relacionadas a dinâmicas de reconversão das funções econômicas das cidades por meio de um empreendedorismo local, além da discussão sobre a produção e o consumo cultural e suas contraditórias relações que reforçam a dominação de classes. Por último, discute-se o planejamento urbano nos Estudos Organizacionais à luz das obras $O$ direito à cidade, $A$ revolução urbana e $A$ produção do espaço, de Henri Lefebvre.

Como protagonistas de suas discussões, os autores da obra recorrem a diferentes cidades brasileiras para refletir sobre suas problemáticas. Por exemplo, duas favelas com Unidades de Polícia Pacificadora (UPPs) na cidade do Rio de Janeiro (RJ) são abordadas para discutir campos de poder pelo viés da perspectiva bourdieusiana e seus processos de organizar (Czarniawska, 2014). A cidade de Belo Horizonte (MG) é palco para se refletir sobre as transformações que ocorrem na gestão do Mercado Novo, trazendo à tona a construção de identidades inerentes aos espaços urbanos. O bairro de Santa Felicidade, em Maringá (PR), oferece subsídios para problematizar sobre a formação de uma "cidade sem favelas" a partir do "Programa de Desfavelamento Municipal”, que visou a "limpeza na ordem urbana", assim criticando o processo de desenvolvimento neoliberal capitalista. Esse contexto da obra destaca-se porque faz com que o leitor reflita criticamente sobre outras cidades brasileiras que se ergueram sob o signo da modernidade e - almejado "progresso" em busca de uma estética urbana planejada e, por consequência, excluindo os habitantes que não se encaixam nessa conjuntura de "aformoseamento" da cidade. Por conseguinte, as cidades de Tiradentes (MG) e Paraty (RJ) surgem como exemplos para discutir o empreendedorismo local e os processos de reconversão de funções econômicas nas cidades inspirados na "Teoria da Ação Prática" bourdieusiana, a partir dos conceitos de habitus, capital e campo. Outro objeto de estudo interessante apresentado na obra abordou a formação cultural da cidade de Cataguases (MG) sob uma perspectiva histórica, a partir da reflexão sobre o tempo e a construção de espaços urbanos de memória para compreender como a produção dos bens culturais, por exemplo, pode ampliar as fissuras na cidade, tendo como consequência um "círculo privilegiado da cultura".

Por conta dessas relevantes questões e para além da grande protagonista da obra, que é a cidade e seus elementos nos Estudos Organizacionais, o texto, em diversos momentos, chama atenção para um tema transversal sobre a compreensão da cidade a partir da relação entre o centro e suas margens, não apenas considerando uma visão dicotômica e antagônica entre as partes, mas compreendendo outras formas de entendimento, em que essa oposição não se transforme em algo para justificar o abandono estatal e acentuar ainda mais as diferenças, ou seja, torna-se interessante observar que esses espaços não são exteriores ao Estado (Das \& Poole, 2004). A obra é rica em detalhes no que diz respeito às teorias utilizadas e às questões metodológicas, e configura-se como um esforço dos autores em aproximar os diferentes temas à área dos Estudos Organizacionais por meio de uma perspectiva interdisciplinar sobre as questões urbanas das cidades e sua organização. Demonstra, assim, a preocupação dos autores, que tomam a cidade como objeto de estudo que existe e resiste para compreender a dinâmica social e organizacional, expandido os caminhos que fazem da Administração uma ciência social aplicada. 


\section{REFERÊNCIAS}

Czarniawska, B. (2014). A theory of organizing. London, UK: Edward Elgar.

Das, V., \& Poole, D. (Orgs.) (2004). Anthropology in the margins of the state. Santa Fe: School of American Research Press.

Fischer, T. (1996). Gestão contemporânea: Cidades estratégicas e organizações locais. Rio de Janeiro: FGV.
Fischer, T. (1997). A cidade como teia organizacional: Inovações, continuidades e ressonâncias culturais - Salvador da Bahia, cidade puzzle. Revista de Administração Pública, 31(3), 74-88. Recuperado de http://bibliotecadigital.fgv.br/ojs/index.php/rap/article/view/7906

Mac-Allister, M. (2004). A cidade no campo dos estudos organizacionais. Organizações \& Sociedade, 11(n.spe), 171-181. Recuperado de https:// periodicos.ufba.br/index.php/revistaoes/article/view/12642/o

\section{CONTRIBUIÇÃO DO AUTOR}

Todas as etapas do trabalho foram realizadas pelo autor Carlos César de Oliveira Lacerda. 